\title{
PRELOADED REINFORCED CONCRETE BEAM STRESS BLOCK PARAMETERS : A PRELIMINARY APPROACH
}

\author{
Fachreza Akbar $^{1}$, Wisnumurti $^{2}$, Ari Wibowo ${ }^{2}$ \\ ${ }^{1}$ Student / Civil Engineering Department / Engineering Faculty / Brawijaya University \\ ${ }^{2}$ Lecturer / Civil Engineering Department / Engineering Faculty / Brawijaya University
}

\begin{abstract}
Reinforced concrete beam will have tendency to deteriorated after receiving a certain degree of load by leaving plastic strain. Although Many study of plastic strain behavior were performed to establish the behavior of concrete under cylic load such as in seismic activity or under earthquake load there are less information of preloaded concrete stress block has been reported. In this study, the stress block parameter of $\alpha_{\mathrm{re}}$ and $\gamma_{\mathrm{re}}$ have been defined and derived from empirical model of the early and latest study of concrete behaviour under repeated loading. The result shows match behavior of the parameters value both in every unloading strain increments or concrete reloading increments with particular unloading strain. The result $\alpha_{\mathrm{re}}$ are also has been plotted and compared with the previous proposed $\alpha$.
\end{abstract}

Keyword : concrete stress block, repeated loading, concrete pre-loading

\section{INTRODUCTION}

Concrete is a material with widely well known has non elastic proterties with non linearity of stress-strain behavior, and often called brittle material. The non elastic behavior is caused by forming microcracks of concrete in every given stress. Therefore, a reinforced concrete beam will have tendency to deteriorated after receiving a certain degree of load. The regular stress block of concrete derived from stress-strain calculation is no longer precised for stregth calculation. Hence, a new approach for reinforced concrete beam after given preload is needed.

\subsection{Concrete Stress-strain Behavior Under Repeated Loading}

Early studies of concrete has considered that stress strain behavior of concrete is consist of two linear, elastic and brittle [1].The idea is consider the concrete will perfrom in elastic manner until a certain degree of stress than start to form microcraks then failed in brittle manner. However, the development of concrete studies of around 1970s found that cement paste is non linear softening materials and the non linearity is much depend on the constitutive of both cement paste and aggregate. Thus may explain that the concrete doesn't has elasticity like the steel does. The behavior make concrete having a permanent plastic deformation after given load.

Extensive observations were also has been conducted to establish the relationship of concrete after given load and the stress-strain behavior after receiving load [2] [3] [4] [5] [6]. On the references, the term $\varepsilon_{\mathrm{pl}}$ of plastic strain is used to describe the permanent deformation in the term of length or size extension of concrete after given pre-load. Common scheme of concrete given repeated loading is shown in Figure 1. The studies has also shown that the curve of repeated loading will always form the envelope curve of stress-strain curve of concrete under monotonic loading [3] [6]. Many study of this plastic strain behavior were performed to establish the behavior of concrete under cylic load such as in seismic activity or under earthquake load.

Early study of concrete stress-strain behavior of concrete under repeated loading has found that $\varepsilon_{\mathrm{pl}}$ always formed after a body of concrete is stressed and unloaded. The reference [5] has established the formula of $\varepsilon_{\mathrm{pl}}$ as expressed on equation (1). 


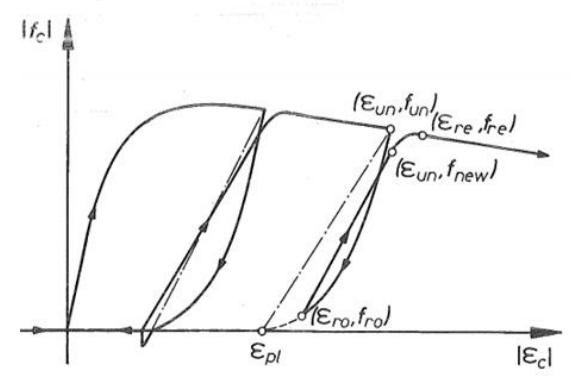

Figure 1. Keypoint of Concrete Stress-Strain under Repeated Loading

$$
\varepsilon_{p l}=\varepsilon_{u n}-\frac{\left(\varepsilon_{u n}+\varepsilon_{a}\right) f_{u n}}{\left(f_{u n}+E_{c} \varepsilon_{a}\right)}
$$

The term $\varepsilon_{\mathrm{a}}$ is the intersection of the initial slope tangent and the plastic unloading secant. As the early study using graphical approach to determine the $\varepsilon_{\mathrm{pl}}$, slighly earlier study [6] has been established the plastic strain as function of unloading strain $\varepsilon_{\text {un }}$ and peak stress strain $\varepsilon_{0}$ with proposed unloading constant value of $\mathrm{k}_{\mathrm{u}}$ as expressed in equation (2).

$$
\varepsilon_{p l}=\varepsilon_{0}\left(\frac{\epsilon_{u n}}{\epsilon_{0}}-k_{u n}\left[1-e^{-\epsilon_{u n} /\left(k_{u n} \varepsilon_{0}\right)}\right]\right)
$$

Curve start from the unloading point to the plastic strain point may also be expressed as equation (3) as unloading curve, and equation (4) as reloading curve [2].

$$
\begin{aligned}
& f_{c}=f_{u n}\left(\frac{1-\left[\left(\varepsilon_{c}-\varepsilon_{u n}\right) /\left(\varepsilon_{p l}-\varepsilon_{u n}\right)\right]}{1+1.2\left[\left(\varepsilon_{u n}-\varepsilon_{u n}\right)\left(\varepsilon_{p l}-\varepsilon_{u n}\right)\right]}\right)^{1.2} \\
& f_{c}=f_{r o}+E_{r}\left(\varepsilon_{c}-\varepsilon_{p l}\right)
\end{aligned}
$$

With $\mathrm{E}_{\mathrm{r}}$ is slope function of $\varepsilon_{\mathrm{un}}, \varepsilon_{\mathrm{pl}}$ and $\mathrm{f}_{\text {new }}$ and $\mathrm{f}_{\mathrm{ro}}$ expressed in equation (5)

$$
E_{r}=\frac{f_{\text {ro }}-f_{\text {new }}}{\varepsilon_{p l}-\varepsilon_{u n}}
$$

with,

$$
f_{\text {new }}=f_{\text {un }}\left[1-0.09\left(\frac{\epsilon_{\text {un }}}{\varepsilon_{\text {ro }}}\right)^{0.5}\right]
$$

\subsection{Concrete Stress Block Parameters}

Under monotonic load, ultimate strength analysis of normal reinforced concrete or considered no significant preload has been given, can be calculated using internal moment couple of the steel tension and concrete compression. Concrete compression usually assumed as a stress block which has been established by early study of reinforced concrete beam [7]. Very much easier of stress block with rectangular shape, which also known as whitneys rectangular stress block has been characterizing and simplying the regular and empirical stress block [8] [9] and has been used in the code [10].

However, the rectangular modified stress block is only available for ultimate strength analysis calculation. For incremental load strength calculation and under service load behavior analysis as shown in Figure 3, the base curved stress block shape [4] [9] which could describe the stress block development on each step of loading is much more convinience to be used. The analysis has been performed and summarized on the references [7].

The curved stress block was derived from stress-strain analysis. Using stress block area parameter and stress block centroid parameter of $\alpha$ and $\gamma$ respectively, the magnitude and position of stress resultant on reinforced concrete under flexure load can be calculated [4].

$$
\begin{gathered}
f_{c}=f^{\prime}{ }_{c}\left[\frac{2 \epsilon_{c}}{\epsilon_{0}}-\left(\frac{\epsilon_{c}}{\epsilon_{0}}\right)^{2}\right] \\
\alpha=\frac{\int_{0}^{\epsilon_{c m}} f_{c} d \epsilon_{c}}{f^{\prime}{ }_{c} \epsilon_{c m}}
\end{gathered}
$$

Equation (8) express the $\alpha$ parameter as the intergral of area under stress-strain curve divided by maximum concrete stress multiplied by its strain at maximum. Thus create a $\mathrm{f}^{\prime} \mathrm{c}$ function. On the other hand, $\gamma$ is simply the centroid of the stress block area. The centroid means the resultant point of all concrete compression stress with well known scheme is shown in Figure 2. $\mathrm{Z}$ as expressed in equation (10) is the confinement parameter which will define the softening branch of concrete stressstrain curve [4].

$$
\begin{aligned}
& \gamma=1-\frac{\int_{0}^{\epsilon_{c m}} \epsilon_{c} f_{c} d \epsilon_{c}}{\epsilon_{c m} \int_{0}^{\epsilon_{c m}} f_{c} d \epsilon_{c}} \\
& Z=\frac{0.5}{\frac{3+0.29 f^{\prime} c}{145 f^{\prime} c-1000}+\frac{3}{4} \rho_{s}\left(\sqrt{\frac{b^{\prime \prime}}{S_{h}}}\right)-\epsilon_{0}}
\end{aligned}
$$


Thus, explaining the stress block parameter of normal reinforced concrete beam. However, althougth vast observations of concrete behavior under repeated and cyclic loading have been done, there are less information of preloaded concrete stress block has been reported.

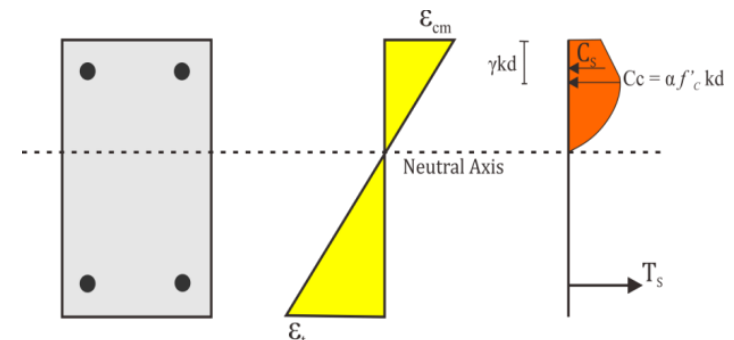

Figure 2. The use of area and centroid parameters in concrete stress block

\section{PRELOADED REINFORCED CONCRETE BEAM MODEL}

\subsection{Normal concrete stress-strain model}

In the study of repaired reinforced concrete beam [11] laboratory experiment has been conducted to observe the behavior of preloaded beam repaired using several repair system. The used reinforced concrete beam built with fc' equal $34 \mathrm{Mpa}$ with $\phi 8 \mathrm{~mm}$ diameters stirrups in every $100 \mathrm{~mm}$ length for its confinement. Using equation (10) $\mathrm{Z}$ for the stirrups result value of 35.2.

Then the stress-strain curve model of the concrete with the values yielded Table by using equation (7) as proposed in the reference [4]. The curve is stress-strain curve which can be derived to stress block for normal concrete, or un-preloaded reinforced concrete beam.

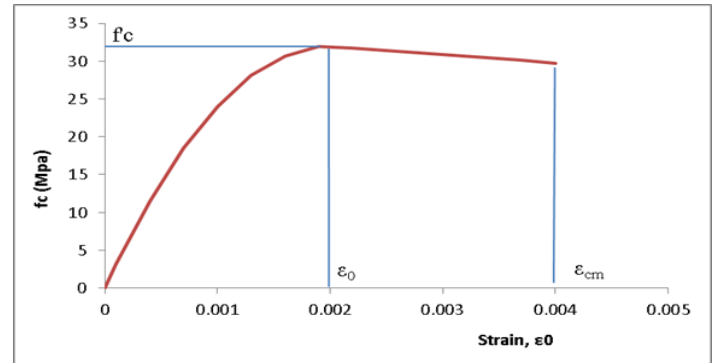

Table 1. Stress-Strain curve model of fc' $34 \mathrm{Mpa}$ and $\mathrm{Z}=35.2$

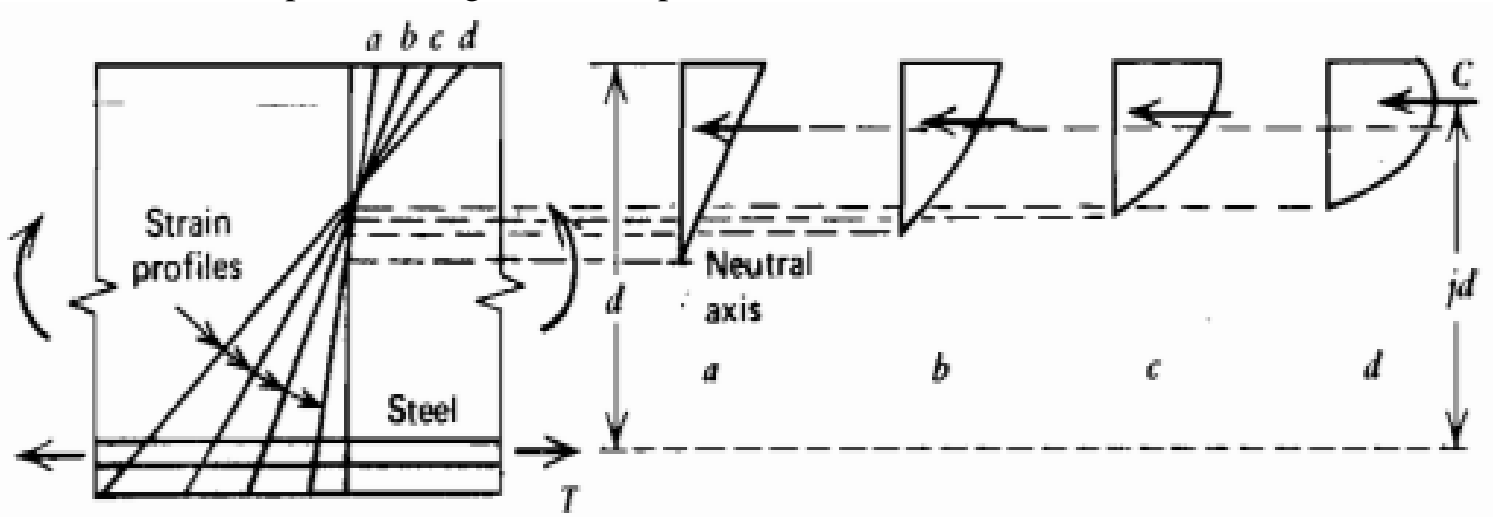

Figure 3. Development of stress block on every increasing of beam moment (a,b,c, and d)

\subsection{Repeated loading stress-strain curve model}

Using equation (1) to (6) the repeated loading of the concrete with $\varepsilon_{\mathrm{c}}$ increments may result on unloading-reloading curve model as shown in Figure 4. From the unloading and reloading curve, it may shown that the concrete will deteriorate after given preload. The deterioration may shown that the concrete will not back to the original stress where the latest unloading strain of $\varepsilon_{\text {un }}$ is given. Then more strain is needed to reach slighly lower stress level than the unloading stress of $f_{\text {un }}$. This behavior has been confirmed with the result of many experiment prior established [2] [3] [6].

$\mathrm{f}_{\text {new }}$ is stress point with the strain is reach the same magnitude to the unloading strain. Assuming that maximum strain will only reach 0.004 on reloading which the top fiber of the beam cross section already reach 0.004 on preloading, then all the concrete increments from the neutral axis to the top concrete fiber will only reach to the $f_{\text {new }}$ point. The line of $f_{\text {new }}$ resulted on Figure $\mathbf{4}$ may be reploted as Figure 6. 


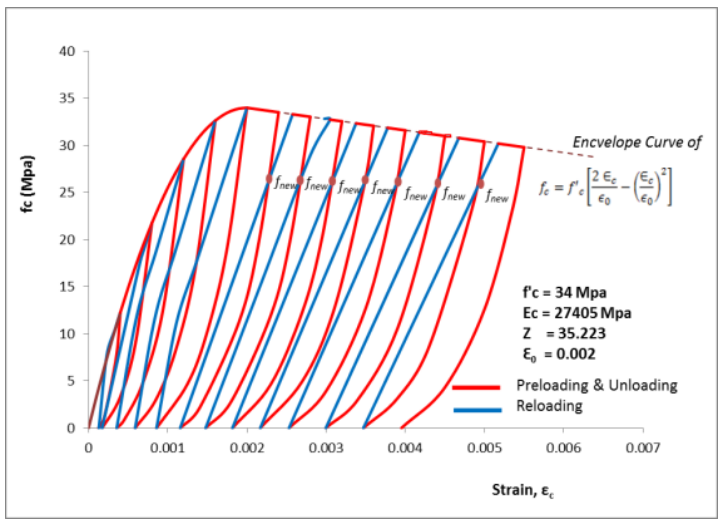

Figure 4. Repeated Stress-strain model of the repeated load with $\varepsilon_{\mathrm{c}}$ increments

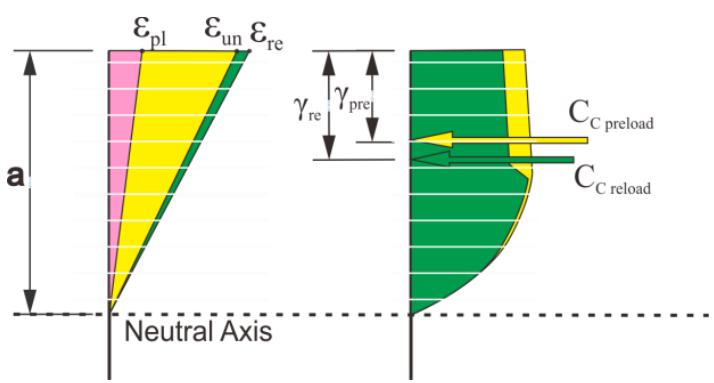

Figure 5. Strain and stress development along the distance from neutral axis

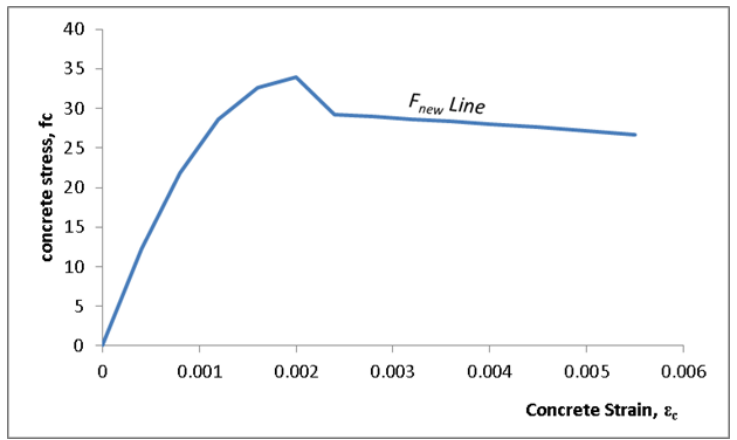

Figure 6. $\mathrm{f}_{\text {new }}$ line after given preloading and unloaded at $\varepsilon_{\text {un }} 0.004$ and reloaded to $\varepsilon_{\text {re }} 0.004$

From the model, the $\mathrm{f}_{\text {new }}$ is built up with lower stress magnitude than original concrete stress if the unloading strain pass the maximum stress strain of $\varepsilon_{\mathrm{y}} 0.0002$. for concrete ith $34 \mathrm{Mpa} \mathrm{fc}$ ' and $35.2 \mathrm{Z}$, with unloading strain 0.004 and reloading strain up to 0.004 the plot of envelope stress-strain curve may be shown as Figure 6.

\subsection{Parameters for preloaded reinforced concrete beam stress block}

As seen in Figure 6 that difference area under the curve is well noticable, the value of parameter $\alpha$ and $\gamma$ will have different magnitude when stress block is plotted. As prior discussed that different stress-strain curve outcome will be produced by different unloading strain.

Introducing $\alpha_{\mathrm{re}}$ and $\gamma_{\mathrm{re}}$ as the stress block parameters for prior preloaded beam.

$\alpha_{\mathrm{re}}$ and $\gamma_{\mathrm{re}}$ is the stress block factor parameters and centroid stress block factor parameters of prior preloaded reinforced concrete beam, respectively.

$$
\alpha_{r e}=\frac{\int_{0}^{\epsilon_{c m}} f_{c r e} d \epsilon_{c}}{{f^{\prime}}^{\prime} \epsilon_{c m}}
$$


$\alpha_{\mathrm{re}}$ is simply produced by deviding the area under stress-block curve by fc' multiplied by strain of concrete when reaching its maximum stress, as expressed in equation (11). while $\gamma_{\mathrm{re}}$ is the $\mathrm{Y}$ axis centroid of the area under stress block.

To define $\alpha_{\mathrm{re}}$ and $\gamma_{\mathrm{re}}$ for every increment of unloading strain, stress block curves for each increments of $\varepsilon_{\mathrm{pl}}$ and constant $\varepsilon_{\mathrm{re}}$ are plotted. Using plotting and drawing software such as autocad, the summary of stress block curves are presented in

. In the plot, increment of $\varepsilon_{\text {un }} 0.00025$ is employed, however for the paper reading con vinience, onlye several curve plot is presented. Finer increment plot is presented in the reference [11].

The relationship of $\varepsilon_{\text {un }}$ and resulted on $\alpha_{\text {re }}$ is plotted in Figure 8 with polynomial trendline. The trendline show that $\alpha_{\text {re }}$ is almost constant around 0.81 when unloading strain is below 0.0036 and start to decrease after pass it. More prior unloading strain is given to the concrete, with reloading strain is not exceeding the unloading strain, the resulted $\alpha_{\text {re }}$ is much lower, means that the area of stress block are smaller than original stress block. $\alpha_{\text {re }}$ for the increments with $34 \mathrm{Mpa}$ of fc' and Z 35.2, the polynomial formula is presented on equation (12) and result on $\alpha_{\mathrm{re}} 0.75$ for $\varepsilon_{\mathrm{un}} 0.004$ and $\varepsilon_{\mathrm{re}} 0.004$. Although this trendline is derived from empirical model of repeated loading of concrete, the result may explain the behavior of prior observed behavior in the earlier studies.
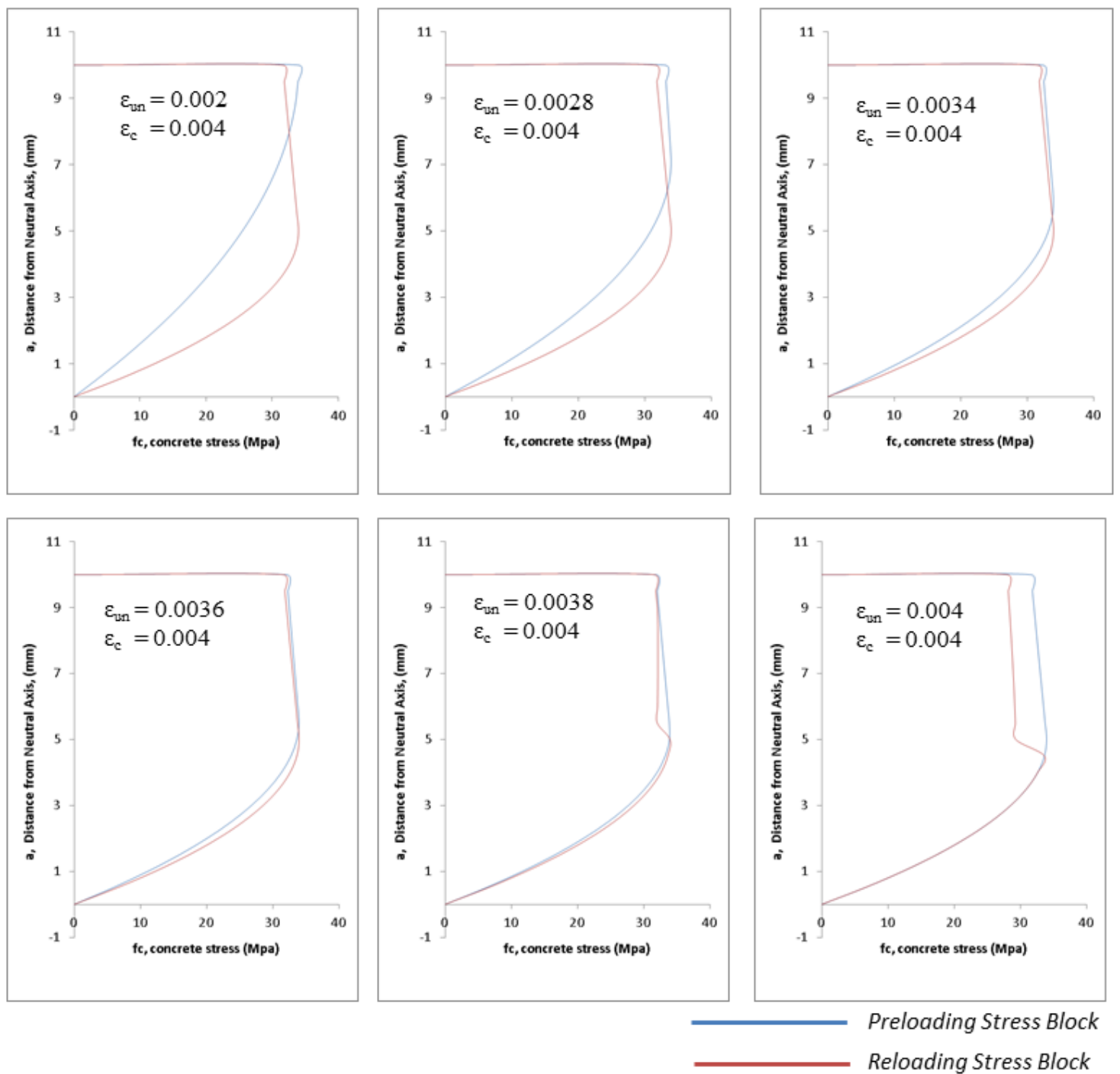

Figure 7. Stress block plot for increment of unloading stress created by $\varepsilon_{\mathrm{pl}}$ and constat $\varepsilon_{\mathrm{re}} \max$ reloading strain 
$\alpha_{\text {re }}=-65,399,070.65 \varepsilon_{\text {un }}^{3}+563,835.19 \varepsilon_{\text {un }}$

2 - $1,591.15 \varepsilon_{\text {un }}+2.28$

$\gamma_{\mathrm{re}}$ with the same incremental plot has result increasing trendline with more given unloading strain showed by Figure 9. The increasing $\gamma_{\mathrm{re}}$ is simply caused by the moved centroid closer to the neutral axis in every decrease of stress-block area.

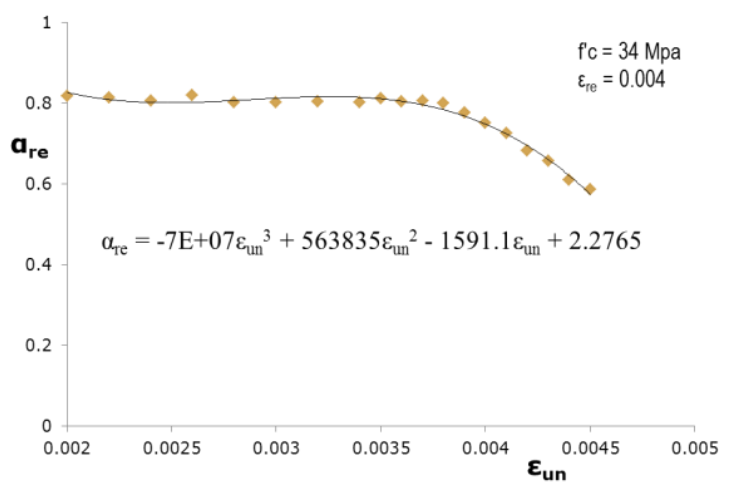

Figure 8. Trendline of $\alpha_{\text {re }}$ on each increment of $\varepsilon_{\text {un }}$ and constant $\varepsilon_{\text {re }}$ of 0.004

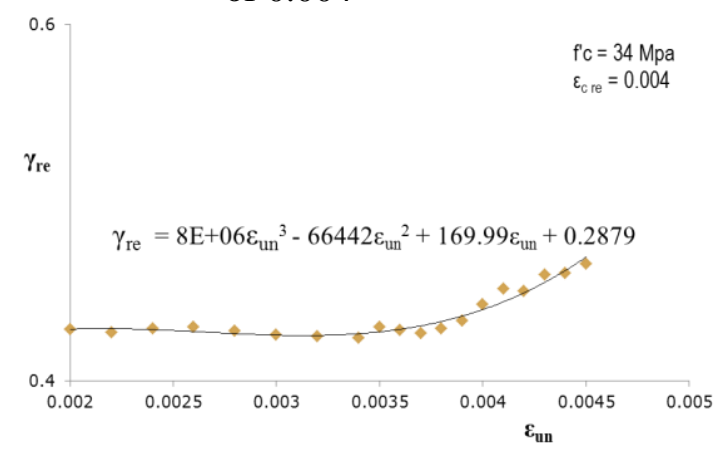

Figure 9. Trendline of $\gamma_{\mathrm{re}}$ on each increment of $\varepsilon_{\text {un }}$ and constant $\varepsilon_{\text {re }}$ of 0.004

\section{$2.4 \alpha_{\mathrm{re}}$ and $\gamma_{\mathrm{re}}$ for incremental given load}

Service load behavior with increment of load analysis need stress block development as explained in Figure 3. The stress block parameters that will change in every increments of load or beam moment is the $\alpha$ and $\gamma$.
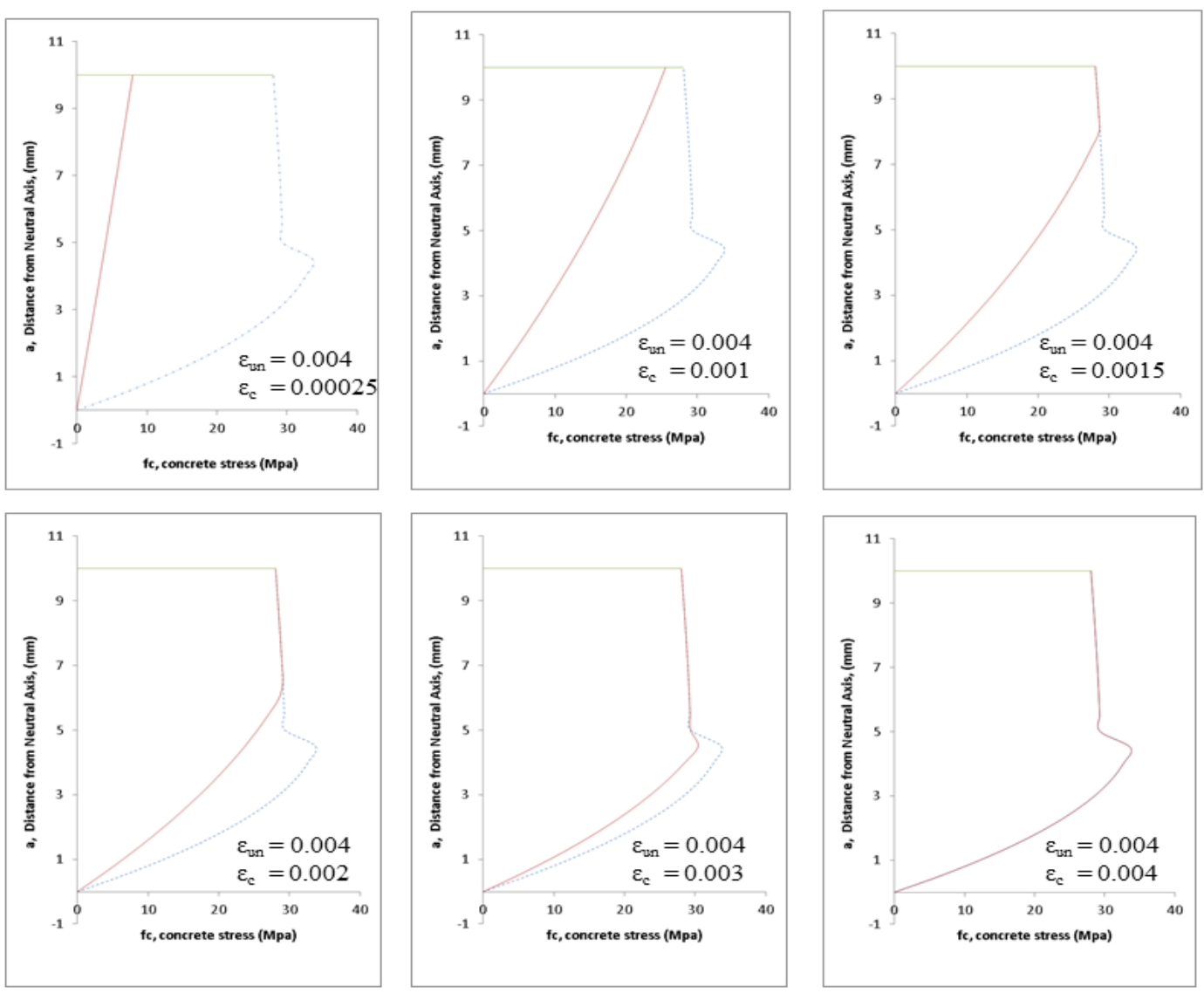

Preloading Stress Block

Reloadina Stress Block

Figure 10. Stress Block on reloading curve on increment of $\varepsilon_{\mathrm{c}}$ with $\varepsilon_{\text {un }} 0.004$ 


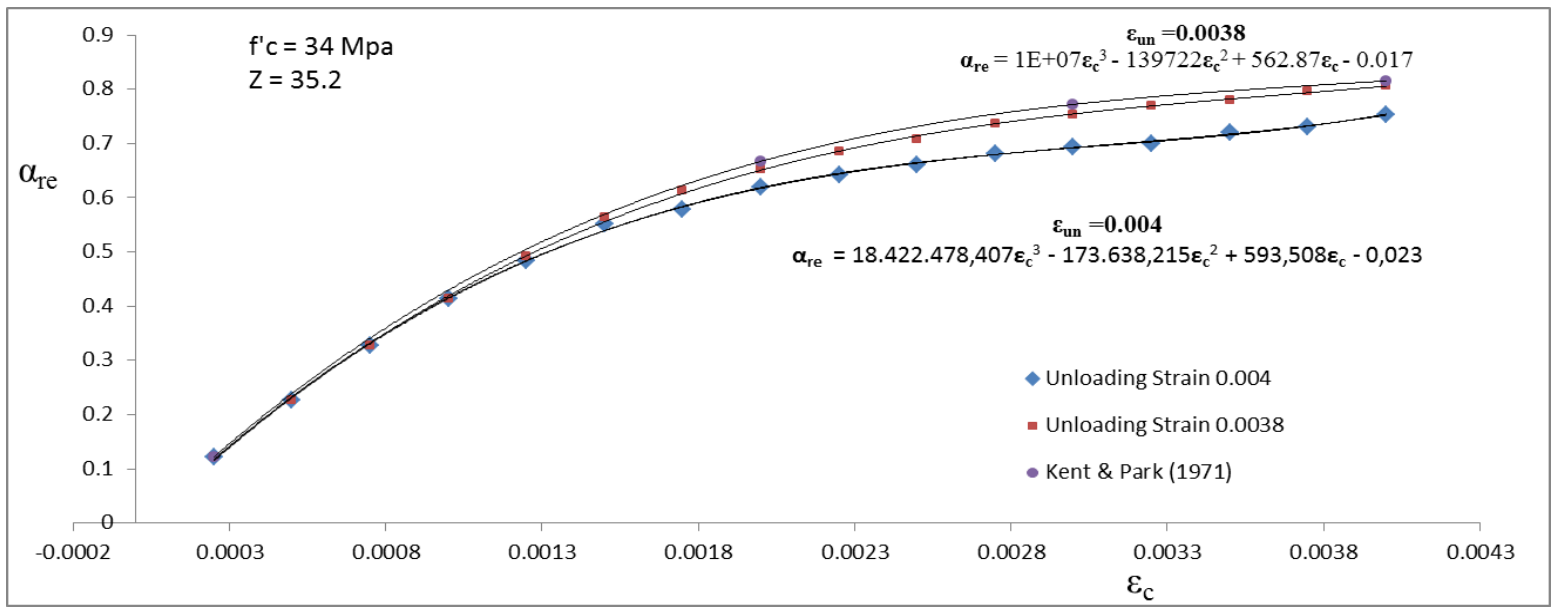

Figure 11. Trendline of $\alpha_{\text {re }}$ with increment of given stress or beam load

It is well observable that changing area and changing area centroid will always happen during every increasing of load. To perform incremental load analyis which are needed for the beam calculated by considering its reinforcement hardening, $\alpha_{\mathrm{re}}$ and $\gamma_{\mathrm{re}}$ are also needed to defined.

Using the same way with the procedure to yield

, increments of $\varepsilon_{\text {re }}$ are given, started with low concrete strain of 0.00025 to maximum estimated concrete strain of 0.004 . The procedure are used to analysis two unloading strain of 0.0038 and 0.004 . Finer increment plot was presented in the reference [11]. Area and centroid of the increment stress blocks are plotted, and with the same way to calculate $\alpha_{\text {re }}$ and $\gamma_{\mathrm{re}}$ Figure 11 and Figure 12 are yielded.

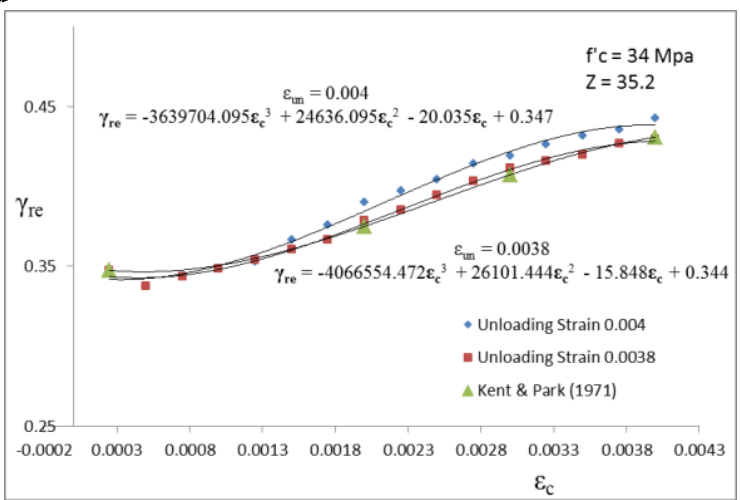

Figure 12. Trendline of $\gamma_{\mathrm{re}}$ with increment of given stress or beam load

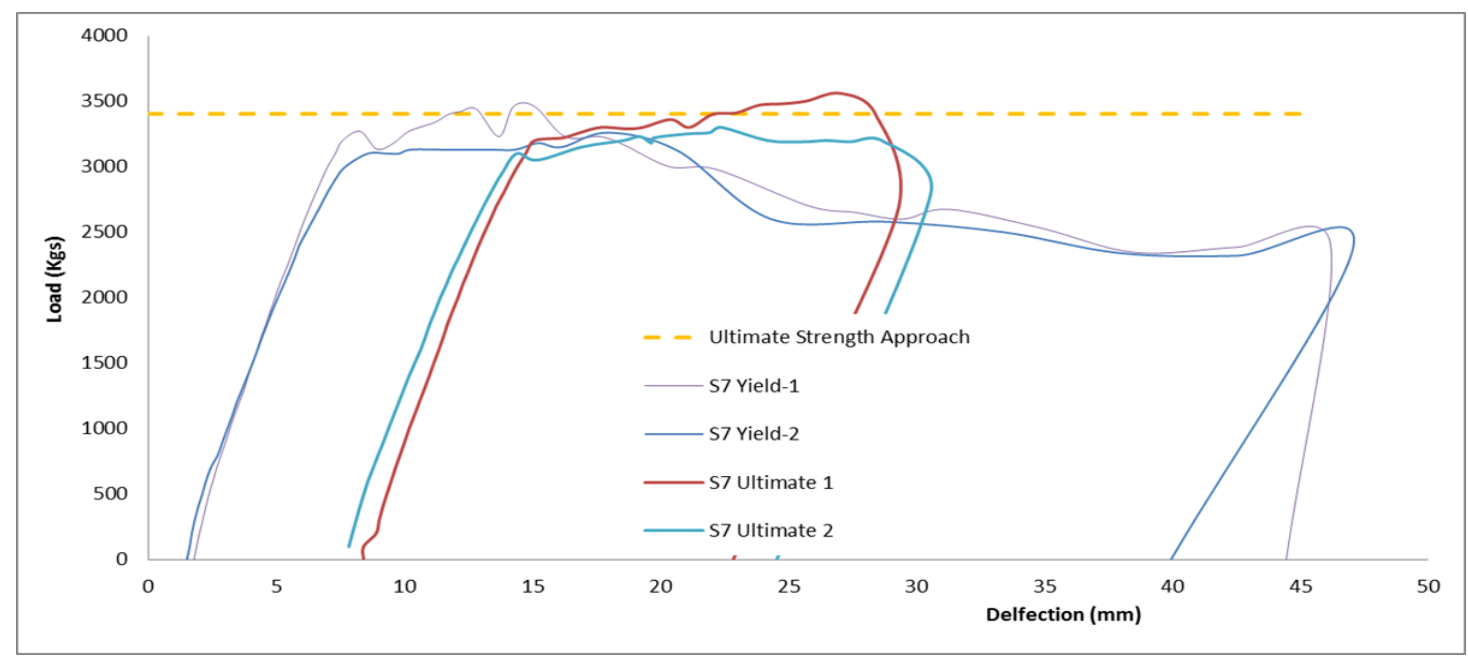

Figure 13. Plotted Ultimate Strength using $\alpha_{\mathrm{re}}$ and $\gamma_{\mathrm{re}}$ 
$\alpha$ and $\gamma$ provided by earlier references [4] [7] are also plotted to the graph tow show the significances of preloading effect on stress block parameter.

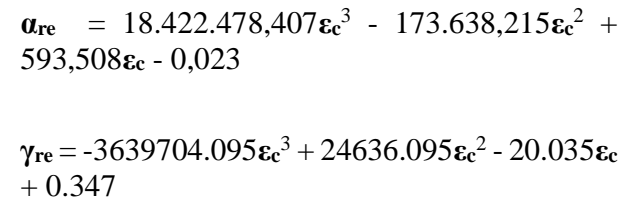

\section{5 $\alpha_{\mathrm{re}}$ and $\gamma_{\mathrm{re}}$ in repaired prior preloaded reinforced concrete beam analysis}

Using defined increment of $\alpha_{\mathrm{re}}$ and $\gamma_{\mathrm{re}}$, ultimate strength of repaired preloaded reinforced concrete beam is plotted on Figure 13. Plotted Ultimate Strength using $\alpha_{\mathrm{re}}$ and $\gamma_{\mathrm{re}}$

and showing closer ultimate strength approach to the tested repaired beam. The parameters is used as changing value on each increment of $\varepsilon_{c}$ in the iteration analysis provided in the reference [11]. The equation (13) and (14) is employed on the iteration analysis.

\section{CONCLUSION}

Concrete is a non-linear and inelastic material which tend to leave plastic strain in after every given loading. The stress block of $\alpha_{\mathrm{re}}$ and $\gamma_{\mathrm{re}}$ have been defined and derived from empirical model of the early and latest study of concrete behaviour under repeated loading. The result shows match behavior of the parameters value both in every unloading strain increments or concrete reloading increments with particular unloading strain.

The result $\alpha_{\text {re }}$ are also has been plotted and compared with the previous proposed $\alpha$. The plot show that stress block on preloaded beam will result significant difference magnitude with increasing $\varepsilon_{\mathrm{c}}$ than stress block of normal concrete without prior preload.

However, despite the match behavior with many established flexural beam theories, this proposed model only developed using previously proposed model for the laboratory experiment analysis approach for the reference [11]. More comprehensive experiment which focusing on examine the proposed paramterers in needed.

\footnotetext{
4. SYMBOL AND NOTATION

$\alpha=$ Stress block area parameter

$\gamma=$ Stress block centroid parameter

$\alpha_{\mathrm{re}}=$ Reloading stress block area parameter

$\gamma_{\mathrm{re}}=$ Reloading stress block centroid parameter

$\varepsilon_{\mathrm{c}}=$ Concrete strain
}

$\varepsilon_{0}=\left(\varepsilon_{\mathrm{cm}}\right)$ Concrete strain when the concrete reach its maximum stress

$\varepsilon_{\text {re }}=$ Reloading strain

$\varepsilon_{\mathrm{pl}}=$ Concrete plastic strain

$\varepsilon_{\text {un }}=$ Unloading strain

$\mathrm{fc}=$ Concrete stress

$\mathrm{fc}^{\prime}$ = Max.Compression stress of 28days concrete cylinder

$\mathrm{f}_{\mathrm{ro}}=$ Concrete stress of after partial released load

$\mathrm{f}_{\mathrm{un}}=$ Unloading stress of concrete

$\mathrm{Z} \quad$ = Confinement by stirrup parameter

\section{REFERENCES}

1 ACI-Committee-224. ACI 224R-01 Control of Cracking of Concrete Structures. Farmington Hills: American Concrete Institute; 1998.

2 Aslani F, Jowkarmeimandi R. Stressstrain model for concrete under cyclic loading. Magazine of Concrete Research. 2012;64(8):673-685.

3 Barros JAO, Cruz JMS, Delgado RM, Costa AG. REINFORCED CONCRETE UNDER CYCLIC LOADING. In: $12 \mathrm{Th}$ World Conference on Earthquake Engineering; 2000; Auckland.

4 Kent DC, Park R. Flexural Members with Confined Concrete. Journal of Structural Division. 1971 1969-1990.

5 Mander JB, Priestley MJN, Park R. Theoretical Stress-Strain Model for Confined Concrete. Journal of Structural Engineering. 1988 August;114:18041826.

6 Otter DE, Naaman AE. Model for Response of Concrete to Random Compressive Loads. Journal of Structural Engineering. 1989;115:2794-2809. 
7 Park R, Paulay T. Reinforced Concrete Structures. New York: John Wiley \& Sons; 1974.

8 Mattock AH, Kriz LB, Hognestad E. Rectangular Concrete Stress Block Distribution in Ultimate Strength Design. Journal of the American Concrete Institute. 1961 875-928.

9 Hognestad E, Hanson NW, McHenry D. Concrete Stress Distribution in Ultimate Strength Design. Journal of American Concrete Institute. 1955;52:455.

10 Commitee-318 A. Building Code Requirements of Structural Concrete and Commentary. Vol 318-08. American Concrete Institute; 2008.

11 Akbar F. Staple Shape Rebar as Flexural Strength Repair on Preloaded Reinforced Concrete Beam. Unpublished Theses. Malang: Brawijaya University; 2018. 